OPEN ACCESS

Edited by:

Qin Hu,

Shanghai Jiao Tong University, China

Reviewed by:

Michelle Theus,

Virginia Tech, United States Yoon Kyung Choi,

Konkuk University, South Korea

*Correspondence:

Li Zhu

zhul@suda.edu.cn

Specialty section:

This article was submitted to Brain Disease Mechanisms,

a section of the journal

Frontiers in Molecular Neuroscience

Received: 04 January 2022

Accepted: 17 February 2022

Published: 08 March 2022

Citation:

Du H, Xu Y and Zhu L (2022) Role

of Semaphorins in Ischemic Stroke.

Front. Mol. Neurosci. 15:848506.

doi: 10.3389/fnmol.2022.848506

\section{Role of Semaphorins in Ischemic Stroke}

\author{
Huaping $D u^{1}$, Yuan $X u^{1}$ and $L i Z h u^{1,2 *}$ \\ 1 Department of Neurology, Suzhou Ninth Hospital Affiliated to Soochow University, Suzhou, China, ${ }^{2}$ Suzhou Key Laboratory \\ of Thrombosis and Vascular Biology, Jiangsu Key Laboratory of Preventive and Translational Medicine for Geriatric Diseases, \\ Collaborative Innovation Center of Hematology of Jiangsu Province, National Clinical Research Center for Hematologic \\ Diseases, Cyrus Tang Medical Institute, Soochow University, Suzhou, China
}

Ischemic stroke is one of the major causes of neurological morbidity and mortality in the world. Although the management of ischemic stroke has been improved significantly, it still imposes a huge burden on the health and property. The integrity of the neurovascular unit (NVU) is closely related with the prognosis of ischemic stroke. Growing evidence has shown that semaphorins, a family of axon guidance cues, play a pivotal role in multiple pathophysiological processes in NVU after ischemia, such as regulating the immune system, angiogenesis, and neuroprotection. Modulating the NVU function via semaphorin signaling has a potential to develop a novel therapeutic strategy for ischemic stroke. We, therefore, review recent progresses on the role of semphorin family members in neurons, glial cells and vasculature after ischemic stroke.

Keywords: semaphorins, ischemic stroke, neurovascular unit, neurons, glial cells, vasculature

\section{INTRODUCTION}

Ischemic stroke is one of the leading causes resulting in high mortality and substantial loss of neurological function in the world (Tsai et al., 2013). Ischemic stroke occurs due to disruption or significant reduction in the blood flow to a brain region, resulting in permanent neurological deficits or death. Relative to weight, the brain oxygen consumption is very high (accounts for $20-30 \%$ of the total oxygen consumption) and needs more ATP through mitochondrial electron transport chain to maintain cell viability (Dienel and Hertz, 2001; Lin and Powers, 2018). Brain has no energy reserve, and aerobic glycolysis is the brain's principal source of ATP (Cunnane et al., 2020). Therefore, brain is more susceptible to hypoxia. Pathogenic mechanisms following ischemic stroke including excitotoxicity, oxidative stress, inflammation, and apoptosis (Datta et al., 2020). Previous studies highlighted ischemia-induced neuronal damage and neuronal protection has been emphasized during treatment (Wang et al., 2021). Current studies focus on the role of the neurovascular unit (NVU) in the pathophysiological processes of ischemic stroke (Steliga et al., 2020). Regulation of the NVU in multiple ways promotes the rehabilitation of neurological function, such as maintaining blood-brain barrier (BBB) integrity and regulating glial cell activity. A number of studies confirmed that semaphorins affect the prognosis of ischemic stroke by regulating NVU (Wei et al., 2015; Hira et al., 2018; Zhou et al., 2018b; Zhao et al., 2021). Increased evidence indicated that semaphorins regulate cell morphology and physiological function during the development of cardiovascular, immune, endocrine, respiratory and central nervous systems (CNS) (Carulli et al., 2021). Moreover, semaphorins play an important role in the pathological processes of the diseases in these organ systems. In CNS, semaphorins have been shown to be involved in many diseases, and several semaphorin members have been reported to participate in 
pathogenic process of ischemic stroke (Sawano et al., 2015; You et al., 2019; MacKeigan et al., 2020). These evidences point to a role of semaphorins in the regulation of ischemic stroke. Therefore, semaphorins are considered as a promising therapeutic tool in ischemic stroke. In this review, we focus on the role of semaphorins in NVU after ischemic stroke.

\section{THE NEUROVASCULAR UNIT AND STROKE}

Risk factors for ischemic stroke includes age, hypertension, diabetes, atrial fibrillation, hypercholesterolemia, etc. (Tsai et al., 2013; Sarikaya et al., 2015). No matter the precipitating event, the result of ischemic stroke is cerebral cell lacking oxygen and energy, leading to disturbed cellular metabolism until death at the molecular level (Sekerdag et al., 2018). The mechanism for the brain injury caused by ischemia includes excitotoxicity, oxidative, and nitrative stress, inflammation and apoptosis (Khoshnam et al., 2017). Multiple types of cells, including neurons, glial cells, endothelial cells and pericytes, undergo those pathophysiological process and lead to cell destruction finally (Hou and MacManus, 2002). Once ischemia occurs, cells especially neurons are unable to sustain their normal function due to hypoxia. Then, ischemic brain tissue can release inflammatory cytokines, increase oxygen radical and excitatory neurotransmitter production, and disrupt the BBB, which causes further tissue damage (Khoshnam et al., 2017; Jiang et al., 2018). Inhibition of those pathophysiological process can mitigate cell damage (Tao et al., 2020). NVU dysfunction directly promotes the breakdown of the $\mathrm{BBB}$, and present theory emphasizes that NVU repair is important to improve functional recovery, namely neurorepair (Davis et al., 2021; Wang et al., 2021).

NVU is consisted of neurons, glial cells, endothelial cells, smooth muscle cells (SMCs), pericytes, and extracellular matrix (Figure 1A; Iadecola, 2017). Neurons, the core of the NVU, detect very little changes of nutrients and oxygen, transmit associated signals to other cells (Banerjee and Bhat, 2007). Glial cells exert pivotal effects during ischemic stroke. Microglial cells are rapidly activated after ischemic stroke and release inflammatory cytokines which activate astrocytes. Astrocytes, by secreting proinflammatory cytokines, chemokines, and matrix metalloproteinase 9, communicate simultaneously with both neurons and blood vessels and then trigger the remodeling of NVU (Gordon et al., 2008; Lopez-Bayghen and Ortega, 2011). The functional characteristics of astrocytes are altered at the different stages of ischemic stroke. Astrocytes limit brain damage in the acute stages and inhibit axon regeneration in the chronic stages (Xu et al., 2020). Different polarizations of astrocytes also have different functional characteristics under pathological conditions (Liu et al., 2020). Endothelial cells produce vascular active factors to control vascular tone, maintain vascular permeability and integrity of NVU together with SMCs and pericytes (Duchemin et al., 2012). Cross talk between cells in NVU through a complex and delicate network. Integrity of NVU is highly important to maintain the homeostasis of brain microenvironment and regulate cerebral blood flow (Armstead and Raghupathi, 2011).

Brain ischemic injury can stimulate the NVU to activate inflammatory cells, upregulate adhesion molecules, release multiple cytokines such as interleukins-1 $\beta$ (IL-1 $\beta$ ) and tumor necrosis factor- $\alpha$ (TNF- $\alpha$ ) (Wang et al., 2021). Inflammatory factor exacerbates cellular damage and death. Inhibition of inflammatory response can significantly improve the prognosis of stroke. In addition, astrocytes, one of the most important components of NVU, can secrete neurotrophic factors that guide neuronal migration and facilitate neuronal and axonal regeneration (Xu et al., 2020). Therefore, in-depth study of the NVU provides potential target for ischemic stroke treatment.

\section{ROLE OF SEMAPHORINS IN ISCHEMIC STROKE}

Semaphorins are a large family of axon guidance cues, which consist of a sema domain (a specific region of about 500 amino acids), a plexin-semaphorin-integrin (PSI) domain, and distinct protein domains (Figure 2; Kolodkin et al., 1993; Lu and Zhu, 2020). Based on the structure and distribution characteristics, semaphorin family proteins are divided into eight classes ( $\mathrm{Hu}$ and Zhu, 2018; Limoni, 2021). Class 1-2 and class 5C are found in invertebrates, while classes 3-7 are found in vertebrates and class $\mathrm{V}$ is found in virus. In vertebrates, semaphorin 3 and 4 have 7 members, namely A-G; semaphorin 5 has 2 members, named $5 \mathrm{~A}$ and $5 \mathrm{~B}$; semaphorin 6 has 4 members, named $6 \mathrm{~A}$ to $6 \mathrm{D}$; semaphorin 7 has only one member (Hu and Zhu, 2018). In addition, class $1,4,5$, and 6 are bound to the cell membrane through a transmembrane domain; class 2, 3, and $\mathrm{V}$ can be secreted; and class 7 is the only glycosylphosphatidylinositol (GPI)-anchored protein. The structure of semaphorins is shown in Figure 2. The functions of semaphorins are mediated by their receptors plexins and neuropilins (Figure 2; Raper, 2000; Nissen and Tsirka, 2016; Junqueira et al., 2021). Invertebrates have plexins $A$ and $B$, and vertebrates have plexins $A$ to D. However, class 3 mediated signaling requires the binding of both plexins and neuropilins (Hu and Zhu, 2018). Moreover, other molecules, such as Otk (transmembrane protein Off-track) and CD27, work as a part of receptor complex of the semaphorins or directly as their receptors (Winberg et al., 2001; Xue et al., 2016).

Early studies in neurons revealed that semaphorins play attractive or repulsive role in axonal growth, regulating the precise wiring of neural architecture. During the last three decades, semaphorins have been considered as key regulators of cell physiological process in different organ systems, especially in the nervous system, the circulatory system, and the immune system (Carulli et al., 2021). The major function of semaphorins is to modulate cytoskeleton motion and cell adhesion, and thereby affect cell morphology, growth, differentiation, migration and survival (Nakamura et al., 2000). In addition, a great deal of progresses has been made in defining the roles of semaphorins in the regulation of CNS diseases under pathological conditions, such as ischemic stroke. Emerging evidence suggests that semaphorins are involved in the development of atherosclerosis 


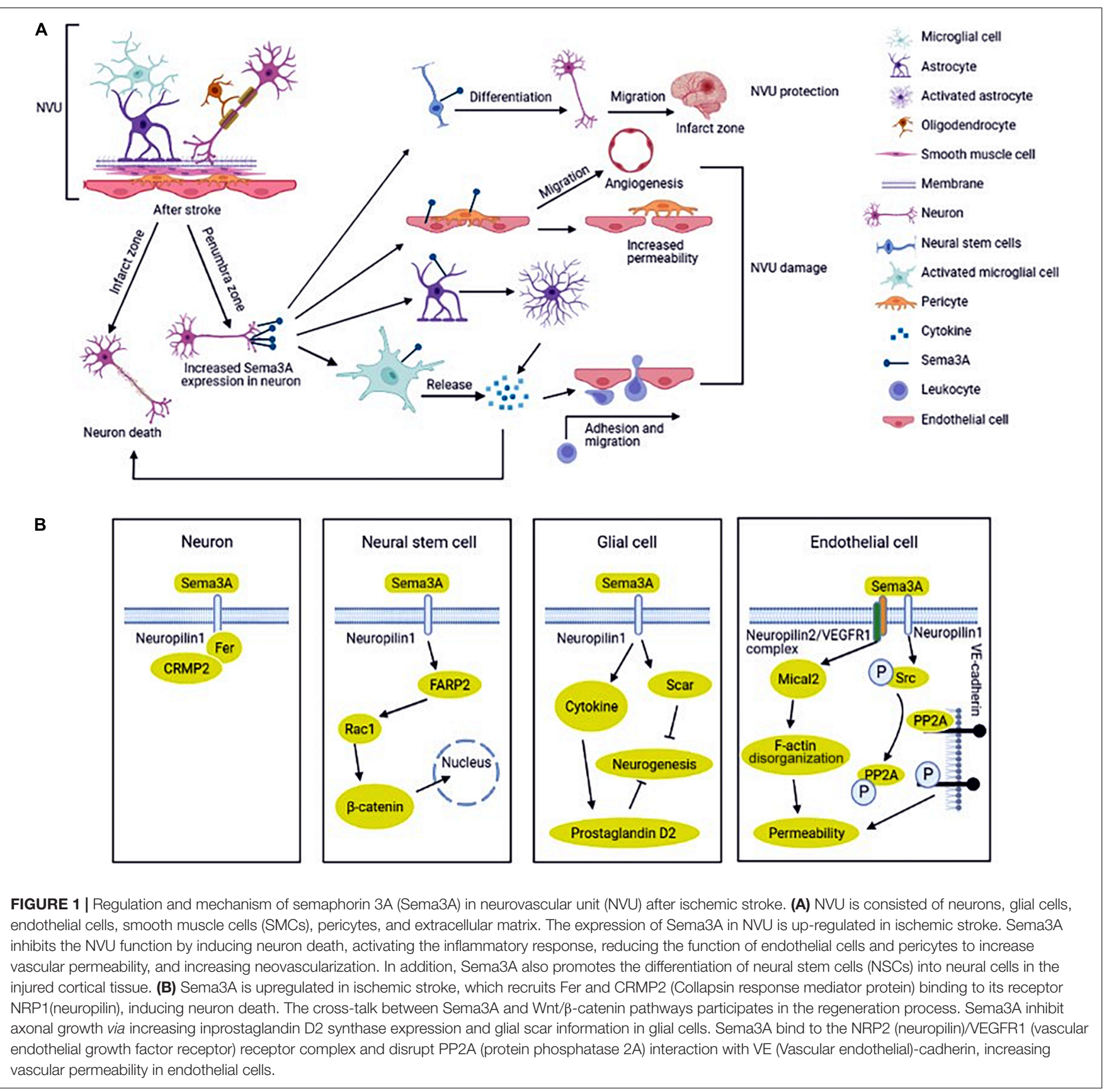

and thrombus formation (Zhu et al., 2007; Hu and Zhu, 2018). Semaphorins act as important regulators of neurogenesis, cell migration, cell apoptosis, vascular morphogenesis, angiogenesis and immune responses in the pathologic process of ischemic stroke (Tian et al., 2009; Limoni and Niquille, 2021; Yu et al., 2021). Semaphorin 3A (Sema3A) and semaphorin 4 D (Sema4D) are important for cell apoptosis, inflammatory response, neurogenesis and angiogenesis. Semaphorin 3B (Sema3B) can affect the integrity of neuron dendritic structure. Semaphorin 3E (Sema3E) suppresses the migration capacity of pericytes toward endothelial cells, increases the vascular permeability, and damnifies NVU. Semaphorin $4 \mathrm{~B}$ (Sema4B) serves as an astrocyte receptor to regulate astrogliosis after ischemic stroke. Semaphorin 6B (Sema6B) and semaphorin 7A (Sema7A) mainly involves in angiogenesis and vascular permeability.

\section{SEMAPHORIN 3A}

Sema3A was first found in the chicken brain and induced the collapse and paralysis of neuronal growth cones (Kolodkin et al., 1993; Luo et al., 1993). It is the prototypical and deeply understood member of the semaphorin family. Sema3A and its receptors (neuropilins and plexins) were found to express 


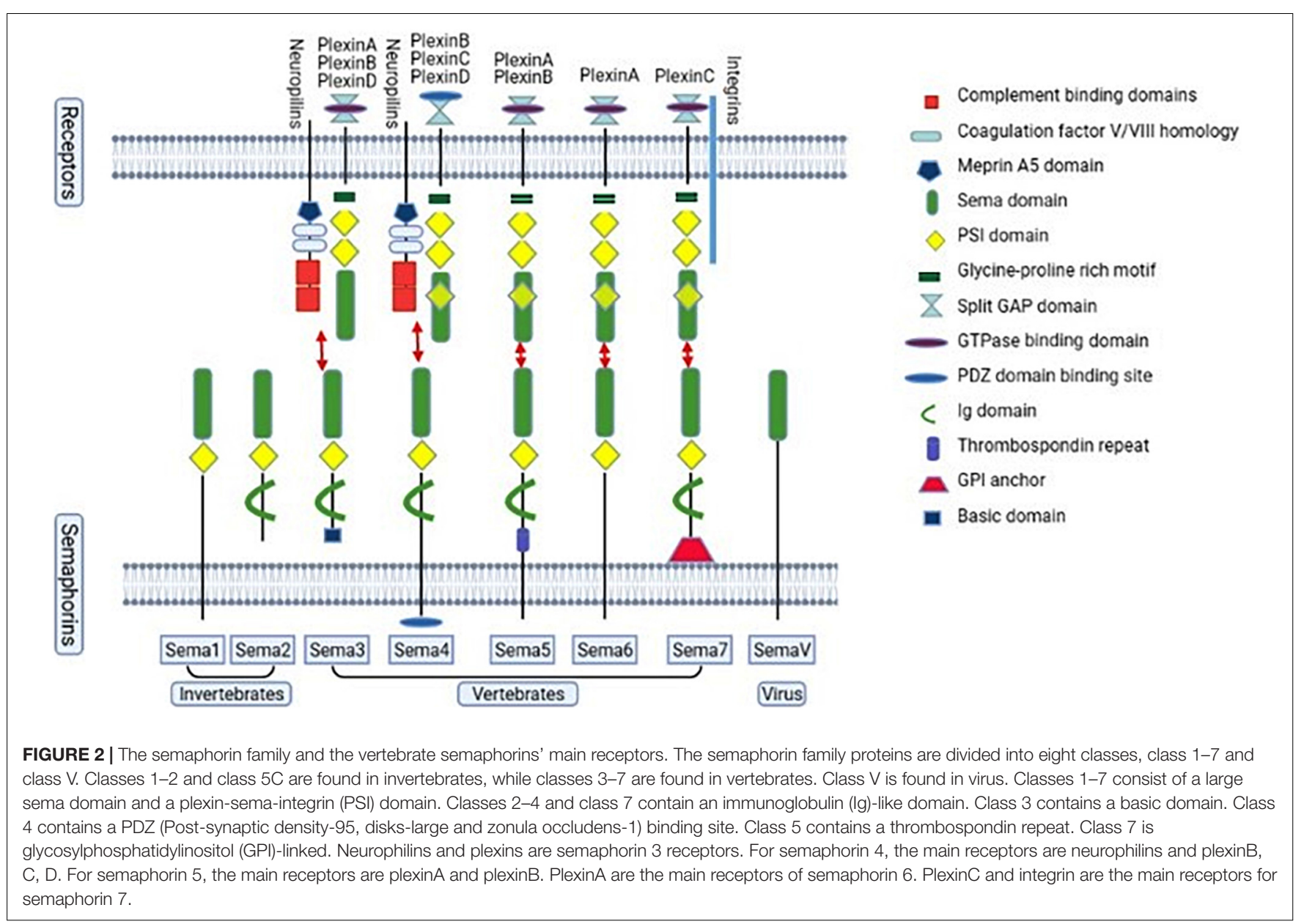

in the nervous system including neurons, microglial cells, astrocytes, endothelial cells and oligodendrocytes (Takahashi et al., 1999; Fujita et al., 2001; Hashimoto et al., 2004). Sema3A binds to its high affinity receptor neuropilins, but the signal cannot be transmitted effectively. The signal delivery process simultaneously requires another receptor plexins to form complex. The complex is responsible for initiating the signal transduction and leading to growth cone collapse and axon repulsion (Nakamura et al., 2000). Sema3A is closely associated with ischemic stroke and affects stroke recovery (Pekcec et al., 2013). Oxygen-glucose deprivation (OGD) is widely used as an in vitro model for stroke, showing similarities with the in vivo models of brain ischemia (Tasca et al., 2015). The expressions of Sema3A and neuropilin (NRP) - 1 in cultured rat cortical neurons are up-regulated after OGD treatment, which in turn take part in the neuron apoptosis (He et al., 2018; Yang et al., 2019). In the middle cerebral artery occlusion (MCAO) model, Fujita et al. (2001) found that the expression of Sema3A and neuropilins is temporally upregulated and could not induce neuron death in the non-infarcted parietal cortex on the lesion side. However, upregulated Sema3A and its receptors, lasting for a longer time, could activate glial cells to induce neuronal death in infarct lesion (Figure 1A; Fujita et al., 2001). Hypoxia increases oxygen radical production in neuronal cells (Khoshnam et al., 2017).
Regulating Sema3A expression can decrease OGD-mediated cell damage by reducing neuronal oxidative stress and apoptosis (Yang et al., 2021; Zhao et al., 2021). A number of studies have indicated that the mechanism involved in cerebral ischemiainduced neuronal death and neurovascular unit damage is NRP1 (not neuropilin-2, NRP2)/Fer/CRMPs (Collapsin response mediator protein) pathway (Figure 1B; Aylsworth et al., 2009; Hou et al., 2009, 2010; Jiang et al., 2010; Whitehead et al., 2010). CRMP has been identified as an intracellular signaling mediator for Sema3A (Makihara et al., 2016). In this signaling, cyclin-dependent kinase $5(\mathrm{Cdk} 5)$ primarily phosphorylates the residues of Ser522 of CRMP2. Glycogen synthase kinase-3 3 (GSK$3 \beta$ ) subsequently phosphorylates the residues of Thr509 and Thr514 of CRMP2 (Nakamura et al., 2018). Another study indicated that the nuclear transcription factor E2F1 plays an important role in modulating neuronal death in response to cerebral ischemia by enhancing the NRP1 level via binding NRP1 promoter sequence (Jiang et al., 2007). Nonetheless, Beck et al. (2002) showed that Sema3A, 3C, and 3F appeared to be strongly downregulated in the infarcted and peri-infarct cortical neurons. The authors speculated that low level of Sema3 in neurons could promoted neuronal reorganization in the peri-infarct area and neurological function recovery following experimental cerebral ischemia (Beck et al., 2002). 
Neurogenesis plays an important role in producing a full recovery of the damaged brain after stroke (Xin et al., 2017; Santopolo et al., 2020; Rahman et al., 2021). It is known that neural stem cells (NSCs) exist in the subventricular zone of the lateral ventricle and the dentate gyrus of the hippocampus and can differentiate into cells including neurons, astrocytes, and oligodendrocytes (Alvarez-Buylla et al., 2002; Arvidsson et al., 2002; Taupin and Gage, 2002). NSCs can be activated by diverse stimuli such as hypoxia (Vecera et al., 2020; Gengatharan et al., 2021). Recent study showed that Sema3A plays a pivotal role in promoting the differentiation of NSCs into neural cells in the injured cortical tissue (Figure 1A). In-depth study has found that the cross-talk between Sema3A and Wnt/ $\beta$-catenin pathways participates in the regeneration process (Figure 1B; Xu et al., 2018). Another study indicated that Sema3A/NRP1 signaling is essential for cell differentiation into various essential cell types at defined target sites (Schwarz et al., 2009).

Glial cells were originally described as structural support in maintaining biological integrity. Accumulating evidence shows that glial cells act as a double-edged sword in the pathophysiology processes of various diseases including stroke (Abe et al., 2020). In the acute stage of ischemic stroke, glial cells activation could remove metabolic waste and produce anti-inflammatory cytokines and growth factors (Wanrooy et al., 2021). In the chronic stage of stroke, axonal regeneration is related to better prognosis. Activation of glial cells and glial scar formation create major inhibitory environments for axonal outgrowth in the peri-infarct area (Qin et al., 2019; Zhu et al., 2021). Astrocytes are involved in various pathophysiological processes in central nervous system (CNS), including homeostasis maintenance, synapse formation, structural support, cerebral blood flow regulation and BBB formation (Jha et al., 2018). Sema3A/NRP signal pathway can activate glial cells to exert phagocytosis which induces neuron apoptosis and participates in glial scar formation in ischemic stroke (Kaneko et al., 2006; Hou et al., 2008; Hira et al., 2018). Further study showed that MCAO rats treated with Sema3A inhibitor showed a significant improvement in motor function compared with the vehicle-treated rats. In addition, activation of astrocytes was suppressed by Sema3A inhibitor treatment. These results indicate that inhibition of Sema3A in the peri-infarct area suppresses activated astrocytes (Figure 1A; Hira et al., 2018). The underlying mechanism of axonal outgrowth is related to axonal GSK-3 $\beta$ expression and astrocyte-derived exosomes with prostaglandin D2 synthase expression (Figure 1B). In addition, Increasing IL-1 $\beta$, released by microglial cells in ischemia, induces microvascular injury through the release of Sema3A from adjacent neurons and it can be reversed by knockdown of Sema3A (Rivera et al., 2013).

Vascular permeability disruption occurs during cerebral ischemia resulting in neuronal damage and prolonged loss of brain functions (Hou et al., 2015; Bernardo-Castro et al., 2020). Endothelial cells were damaged firstly in the ischemic region, which resulted in vascular permeability of damaged $\mathrm{BBB}$ and caused severe inflammation (Krueger et al., 2015; Ko et al., 2020). Sema3A acts as a potent inducer of vascular permeability via activation of NRP1 (Figure 1A; Acevedo et al., 2008). The expressions of Sema3A and NRP1 in endothelial cells after OGD treatment were up-regulated (Yang et al., 2019). However, vascular endothelial cell death was not apparent, which was associated with the increased generation of vascular endothelial growth factor (VEGF) after ischemia. VEGF/NRP signals promote angiogenesis in endothelial cells (Beck et al., 2002). As we know, NRP1 is a common receptor for the Sema3A and VEGF. The observations suggest that vascular NRP1 preferentially confers $V_{E G F}{ }_{164}$ signals, while axonal NRP1 preferentially transmits Sema3A signals (Vieira et al., 2007). Hou et al. (2015) revealed that Sema3A bound to the NRP2/VEGFR1 receptor complex caused disorganization of F-actin stress fiber bundles and increased endothelial monolayer permeability, which contributes to ischemic brain damage (Figure 1B). VE (vascular endothelial)-cadherin expression is crucial for vascular permeability (Gavard, 2009; Treps and Gavard, 2017). Le Guelte et al. (2012) reported that Sema3A inhibits the serine protein phosphatase 2A (PP2A) activity and disrupts PP2A interaction with VE-cadherin, increasing vascular permeability (Figure 1B). Studies have shown that endothelial cells actively participate in synaptic plasticity in specific functional domains of brain to control some functions such as neurogenesis (Giacobini et al., 2014). Wu et al. (2019) found that Sema3A inhibited VSMC proliferation and migration by increasing the NRP1plexinA1 complex and decreasing the NRP1- platelet-derived growth factors receptor (PDGFR)- $\beta$ complex, thus inhibiting phosphorylation of PDGFR- $\beta$.

Pericytes are tightly connected to endothelial cells and distributed at discontinuous intervals in vascular basement membrane to maintain local microvessel characteristics (Hess et al., 2019). In CNS, pericytes contribute to the formation of the blood-brain barrier, and act as sensors of hypoxia and mediate precise responses to protect the vulnerable neurons (Dore-Duffy et al., 2005; Yang et al., 2017). Pericytes play a pivotal role in NVU injury in ischemic stroke (Duz et al., 2007). Casazza et al. (2011) found that Sema3A reduces the number of pericytecoated vessels in tumor blood vessels, which correlated with endothelial cell survival. In ischemic stroke, pericytes respond to ischemia promptly and are involved in various pathological and repair processes. We conjectured that a connection between Sema3A and pericyte dysfunction which leads to the progression of vascular diseases such as stroke (Figure 1).

\section{SEMAPHORIN 3B}

Sema3B, another secreted member of the semaphorins, regulates axonal extension. Neuron dendritic structure in the motor cortex is associated with signal transmission of motor function and cell interaction. Ischemic stroke can damage dendritic structure, such as dendritic spine density, and induce motor deficits (Hartle et al., 2010; Huang et al., 2018). Dendritic spines contain different signaling molecules and machinery required for synaptic transmission and plasticity. Damaged dendritic spines cause cell-cell interaction dysfunction in NVU (Taylor et al., 2015). The L1 family Close Homolog of L1 (CHL1) is important for proper development of cortical networks (Pratte et al., 2003). Mohan et al. (2019) found that CHL1 was colocalized with 
Sema3B in pyramidal neurons and formed a complex with Sema3B receptor NRP2 and plexinA4. Treatment with Sema3BFc decreased spine density but did not induce spine retraction in CHL1-null neurons. This result indicated that CHL1 decreased spine density of cortical pyramidal neurons via stimulation by Sema3B (Mohan et al., 2019). CRMP not only plays a key role in axon guidance, but also regulates dendritic morphogenesis. A study showed that Sema3A signaling also regulated dendritic spine density via both CRMP1 and CRMP2 (Makihara et al., 2016). Another study found that dendritic spine density was decreased in cortical pyramidal neurons treated with semaphorin 3F (Sema3F) (Mohan et al., 2018). Thus, multiple semaphorin members can affect the integrity of neuron dendritic structure caused by ischemic stroke.

\section{SEMAPHORIN 3E}

Sema3E, an $85-$ to $90-\mathrm{kDa}$ protein, was defined in tumor cells to play a role in angiogenesis ( $\mathrm{Hu}$ and $\mathrm{Zhu}$, 2018). At present, Sema3E and its receptors are thought to be closely related to stroke prognosis. Studies indicated that Sema3E and its receptor PlexinD1 inhibit cortical and striatal neurons development (Ding et al., 2011; Oh and $\mathrm{Gu}, 2013$ ). In a rat transient middle cerebral artery occlusion model, Sema3E protein was increased in the penumbra area (Zhou et al., 2018a; Yu et al., 2021). Immunofluorescence study indicated that Sema3E staining is mainly colocalized with neurons and that the receptor PlexinD1 is expressed in endothelial cells in NVU. However, Inhibiting Sema3E signaling improves cerebral perfusion, functional outcome and survival after operation. On the other hand, Sema3E suppresses the migration capacity of pericytes toward endothelial cells, increases the vascular permeability, and damages NVU (Krueger et al., 2015; Zhou et al., 2018a). Mechanistically, Sema3E decreased dynamic deltalike 4 expression via inhibiting Ras-related C3 botulinum toxin substrate 1-induced c-Jun N-terminal kinase phosphorylation (Zhou et al., 2019).

In addition, the characteristics of atherosclerotic plaques are closely related to the development of ischemic stroke. However, upregulated Sema3E promotes plaque development by increasing macrophage migration and promoting macrophage retention and chronic inflammation (Wanschel et al., 2013). Therefore, Sema3E negatively regulates vascular permeability, inducing NVU damage, and inhibiting Sema3E signaling is a novel therapeutic strategy for ischemic stroke.

\section{SEMAPHORIN 4D}

Sema4D, as a classic member of the semaphorin family and negative regulator of axon guidance, also regulates inflammation and angiogenesis by interacting with astrocytes, endothelial cells, and pericytes through its receptors plexins or CD72 (Figure 3A; $\mathrm{Hu}$ and Zhu, 2018). Sema4D was the first semaphorin that was determined to regulate inflammatory and immune response. Immune system functions rely on the interactions between leukocytes and endothelial cells via various adhesion molecules (Heemskerk et al., 2014). Furthermore, Sema4D works not only as a directional cue for endothelial cells migration, but also increases the expression of VEGF or angiopoietins to regulate angiogenesis (Conrotto et al., 2005). We could conclude that both the pathophysiological and neurovascular repair processes of ischemic stroke are strongly associated with the integrity of the NVU and that further investigations into Sema4D treatment targeted at the NVU could expand the therapies against deleterious outcomes following ischemic stroke.

Microglial-released proinflammatory and cytotoxic factors induced secondary brain damage after ischemia, and Sema4D inhibited LPS-induced microglial cells activation and migration (Toguchi et al., 2009). After ischemic stroke, the initial inflammatory response is mediated by the activation and recruitment of microglial cells, and inhibition of glial cells activation alleviates brain damage by ischemia ( $\mathrm{Li}$ and Barres, 2018; Qin et al., 2019). The nitric oxide (NO) which is produced by the ischemia activated inducible nitric oxide synthase (iNOS), affecting cell survival by changing the functions of caspases and metalloproteases (Abdul-Muneer et al., 2013). Sema4D upregulates NO production by inducing IFN- $\beta$ expression in microglial cells in the ischemic cortex (Sawano et al., 2019; Tsuchihashi et al., 2020). In ameboid microglial cells, L-arginine is metabolized by iNOS to synthesize NO through Sema4DRhoA-MAPK/ERK signal (Figure 3B; Bijian et al., 2005; Okuno et al., 2010; Sawano et al., 2015). Decreased Sema4D expression enhances activated-ramified microglial cells proliferation which suppresses neuronal apoptosis in ischemic brain (Sawano et al., 2015). The study also indicated that Sema4D promoted cytotoxic activation of microglial cells in the peri-ischemic cortex (Sawano et al., 2015). Mechanistically, Sema4D/PlexinB1 signaling promotes an inflammatory response in pericytes and microglial cells and increases $\mathrm{BBB}$ permeability via regulating pericytes function after stroke (Zhou et al., 2018b).

Oligodendrocytes, the myelinating cells of the CNS, are involved in the recovery of neurological function by promoting the myelination of the damaged white matter (Poyhonen et al., 2019). A clinical study indicated that patients with SAO had significantly higher white matter hyperintensity compared with other stroke subtypes (Giese et al., 2020). Sema4D was expressed selectively by myelinating oligodendrocytes in the CNS white matter and upregulated after spinal cord lesion (Moreau-Fauvarque et al., 2003). Inhibition of Sema4D expression promotes oligodendrocytes recovery after cerebral ischemia/reperfusion injury in mice (Figure 3B; Wada et al., 2016).

Sema4D is expressed in endothelial cells and monocytes, and involved in endothelial-monocyte interaction, influencing migration and cytokines production (Luque et al., 2015). Under hypoxia, Sema4D expression was upregulated in microvascular endothelial cells. Overexpression of Sema4D significantly increases angiogenesis and inhibits neuron axon myelination (Zhang et al., 2014). Intraplaque neovascularization is important sites where leukocytes and macrophage infiltrate into atherosclerotic plaques and exacerbate atherosclerosis (Perrotta et al., 2021). Unstable atherosclerosis plaques are 


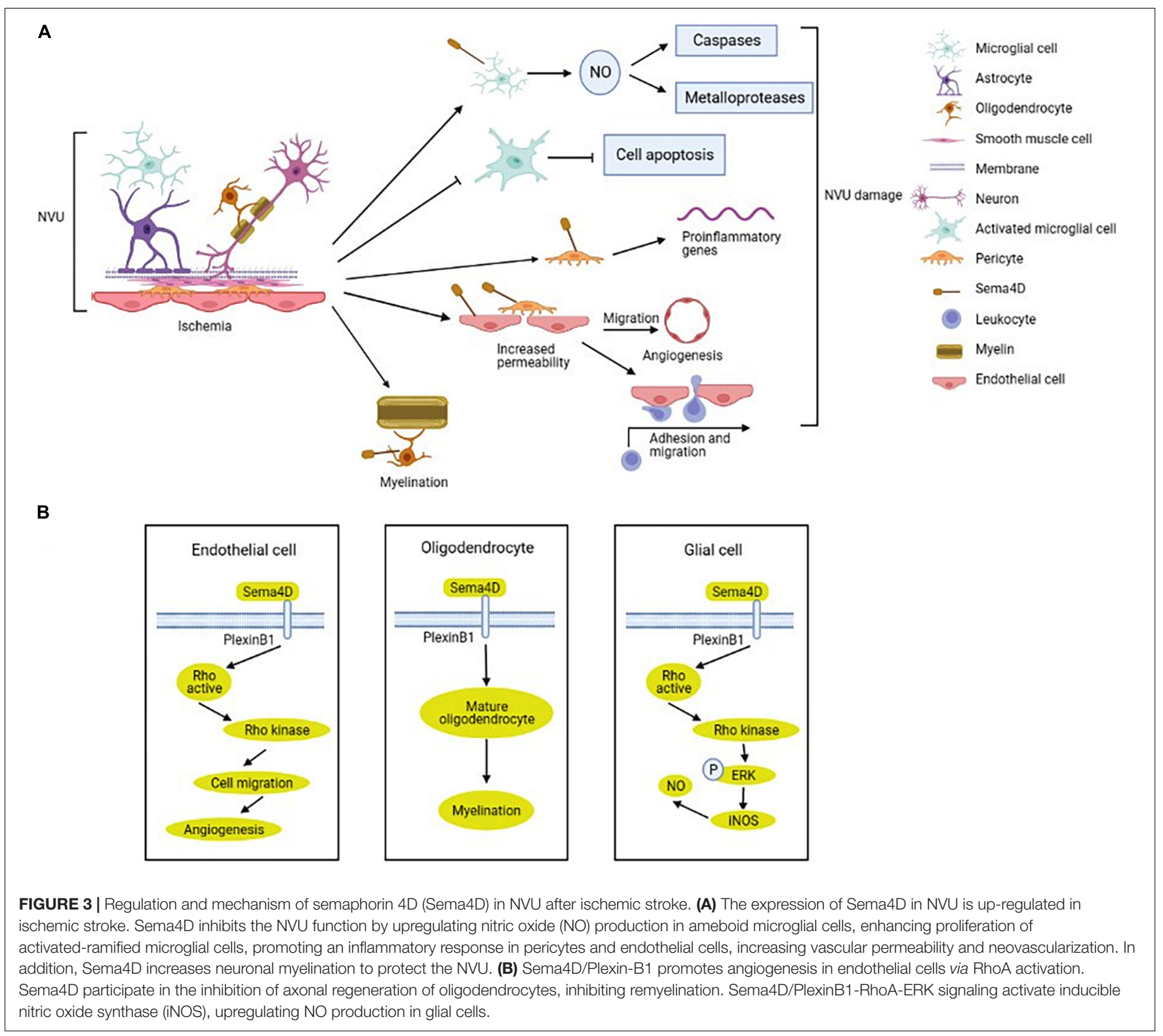

prone to rupture and induce thrombus formation, leading to ischemic stroke (Moreno, 2001). Inhibition expression of Sema4D reduces intimal neovascularization and plaque growth (Zhu et al., 2009; Yukawa et al., 2010). Mechanistically, Sema4D binding to plexinB1 on endothelial cells to guide endothelial cell migration induces intimal growth and angiogenesis (Figure 3B; Conrotto et al., 2005; Zhou et al., 2014). Furthermore, Sema4D also participates in endothelial-platelet interaction, increases endothelial cell permeability, and improves atherogenesis and thrombus formation (Conrotto et al., 2005; Zhu et al., 2007).

\section{SEMAPHORIN 4B}

Sema4B has been identified to be expressed in astrocytes of cortex and involved in the activation of astrocytes in brain injury. Astrocytes undergo dramatic changes in morphology, proliferation and gene expression after an ischemic insult (Choudhury and Ding, 2016). Sema4B significantly inhibited interleukin-4 production in response to various stimuli (Nakagawa et al., 2011). A study indicated that Interleukin-4 improves long-term neurological outcomes after stroke by reducing inflammation in the core and activated astrocytes in the penumbra (Xiong et al., 2011). Another study found that immunomodulation with IL-4 is a promising approach to promote long-term functional recovery after stroke through M2 phenotype induction in microglia/macrophages (Liu et al., 2016). Interaction between activated microglia and astrocytes plays an important role in the process of neuroinflammation after stroke (Liu et al., 2020). Mechanistically, damaged cortex activates astrocytes by phosphorylating the residues of Ser825 of Sema4B (Ben-Gigi et al., 2015). We can speculate that Sema4B serves as 
an astrocyte receptor may regulate astrogliosis after ischemic stroke. In-depth study of Sema4B may provide potential target for ischemic stroke treatment.

\section{SEMAPHORIN 6A}

Semaphorin 6A (Sema6A) regulates axon repulsion and attraction. Sema6A increases tumor angiogenesis via VEGF signaling in vascular endothelial cells (Segarra et al., 2012). Previous studies showed Sema6A was upregulated and improved functional recovery during the recovery phase in cortical ischemia (Kruger et al., 2006; Rogalewski et al., 2010). Good prognosis after stroke is partly associated with neurogenesis and changes in dendritic and synaptic morphology (Keyvani and Schallert, 2002; Santopolo et al., 2020). Like Sema3A, Sema6A also plays an important role in cortical neuronal networks rewiring after ischemia (Rogalewski et al., 2010). A study by Hatanaka et al. (2019) also indicated that Sema6A/plexinA2/A4 signaling regulates migration of superficial layer cortical neurons. Previous study showed that Sema6A mutant mice have corticospinal tract (CST) defect (Okada et al., 2019). Ischemic stroke is often accompanied by CST damage, however, whether Sema6A repairs the damaged CST has not been reported.

\section{SEMAPHORIN 6B}

Human Sema6B is highly expressed in human brain and regulates tumor growth (Correa et al., 2001). Accumulating evidence has been reported that peroxisome proliferator-activated receptor alpha activation modulates vascular integrity and function. It also modulates oxidative stress, blood-brain barrier dysfunction, and neuroinflammation to improve functional recovery from stroke (Boese et al., 2020). Proliferator-activated receptor alpha activation inhibits Sema6B expression and reverses Sema6B induced neuronal cell damage in the CNS (Collet et al., 2004; Inoue et al., 2016). It was reported that sema6B-plexinA4 signal promoted tumor angiogenesis by regulating VEGF-induced VEGFR-2 phosphorylation in endothelial cells (Kigel et al., 2011). We therefore speculate that proliferator-activated receptor alpha modulates the function of endothelial cells via sema6BplexinA4 signal after ischemic stroke. However, the role of Sema6B in cerebrovascular disease has not been demonstrated using animal models.

\section{SEMAPHORIN 7A}

Sema7A, like other semaphorins, positively modulates axon guidance (Pasterkamp et al., 2003). Sema7A is expressed in a variety of neuronal cell types and in glial cells, and involved in multiple processes in the CNS, for example, acting as a potential immune and neuroregenerative target (GutierrezFranco et al., 2017; Jongbloets et al., 2017). Inflammatory responses are aroused by oxidative stress, necrotic cells, and impaired brain tissue (Amantea et al., 2009). Our previous studies indicated that Sema7A expression and its mediated inflammatory immune response in endothelial cells and monocytes participates in the development of atherosclerosis (Hu et al., 2018a,b). Subsequently, we conducted a study to investigate the association of serum Sema7A with atherothrombotic stroke and showed that elevated level of Sema7A is independently associated with atherothrombotic stroke (You et al., 2019). Oxidative stress induces injury of endothelial cells and neurons, and plays an important role in ischemic stroke. Oxidative stress significantly upregulates Sema7A and its receptor $\beta 1$ integrin level, and activates inflammatory responses in endothelial cells (Song et al., 2021). Hypoxia and disruption of the BBB are the pathophysiological features of ischemic stroke, which significantly contribute to neuroinflammation and subsequent neurological disorders. During endothelial cell hypoxia, hypoxiainducible factor- $1 \alpha$ (HIF-1 $\alpha)$ binds the Sema7A promoter hypoxia-responsive element to regulate inflammatory cell

TABLE 1 | Main roles of semaphorins in neurovascular unit (NVU) after stroke.

\begin{tabular}{|c|c|c|c|}
\hline Semaphorins & Cells & Roles & References \\
\hline \multirow[t]{3}{*}{ Sema3A } & Neuron & $\begin{array}{l}\text { Neuron apoptosis, oxygen } \\
\text { radical production, } \\
\text { neurogenesis and cortical } \\
\text { neuronal networks rewiring. }\end{array}$ & $\begin{array}{l}\text { He et al., 2018; } \\
\text { Xu et al., 2018; } \\
\text { Yang et al., } \\
\text { 2021; Zhao } \\
\text { et al., } 2021\end{array}$ \\
\hline & Glia & $\begin{array}{l}\text { Astrocytes activation, glial } \\
\text { scar formation }\end{array}$ & $\begin{array}{l}\text { Hou et al., } \\
2008\end{array}$ \\
\hline & Vasculature & $\begin{array}{l}\text { Endothelial migration and } \\
\text { death, VSMC proliferation } \\
\text { and migration, } \\
\text { angiogenesis, vascular } \\
\text { permeability }\end{array}$ & $\begin{array}{l}\text { Beck et al., } \\
\text { 2002; Acevedo } \\
\text { et al., 2008; } \\
\text { Giacobini et al., } \\
2014\end{array}$ \\
\hline Sema3B & Neuron & Neuron dendritic structure & $\begin{array}{l}\text { Mohan et al., } \\
2019\end{array}$ \\
\hline Sema3E & Vasculature & $\begin{array}{l}\text { Pericytes ability, vascular } \\
\text { permeability }\end{array}$ & $\begin{array}{c}\text { Krueger et al., } \\
\text { 2015; Zhou } \\
\text { et al., 2018a }\end{array}$ \\
\hline Sema4B & Glia & Activation of astrocytes. & $\begin{array}{l}\text { Ben-Gigi et al., } \\
2015\end{array}$ \\
\hline \multirow[t]{2}{*}{ Sema4D } & Glia & $\begin{array}{l}\text { The activation and } \\
\text { recruitment of microglial } \\
\text { cells, inflammatory } \\
\text { response, myelination of } \\
\text { neuron, }\end{array}$ & $\begin{array}{l}\text { Toguchi et al., } \\
\text { 2009; Wada } \\
\text { et al., 2016; Li } \\
\text { and Barres, } \\
2018\end{array}$ \\
\hline & Vasculature & $\begin{array}{l}\text { Regulate } \\
\text { endothelial-monocyte } \\
\text { interaction, endothelial } \\
\text { migration, } \\
\text { neovascularization. }\end{array}$ & $\begin{array}{l}\text { Conrotto et al., } \\
\text { 2005; Zhang } \\
\text { et al., 2014; } \\
\text { Perrotta et al., } \\
2021\end{array}$ \\
\hline Sema6A & Neuron & $\begin{array}{l}\text { Cortical neuronal networks } \\
\text { rewiring }\end{array}$ & $\begin{array}{l}\text { Rogalewski } \\
\text { et al., } 2010\end{array}$ \\
\hline Sema6B & Vasculature & Vascular integrity & $\begin{array}{l}\text { Collet et al., } \\
\text { 2004; Inoue } \\
\text { et al., } 2016\end{array}$ \\
\hline Sema7A & Vasculature & $\begin{array}{l}\text { Activates inflammatory } \\
\text { responses in endothelial } \\
\text { cells, vascular permeability }\end{array}$ & $\begin{array}{l}\text { Morote-Garcia } \\
\text { et al., 2012; Hu } \\
\text { et al., 2018b; } \\
\text { Song et al., } \\
2021\end{array}$ \\
\hline
\end{tabular}

2021 
migration and leukocyte extravasation from the vascular space (Morote-Garcia et al., 2012).

\section{OTHER MEMBERS OF SEMAPHORIN FAMILY}

In addition to the members of semaphorin family described above, other semaphorins may be involved in the process of ischemic stroke as well although there was no report so far. Semaphorin 3C (Sema3C) and semaphorin 3D (Sema3D) play an important role in tumor development by regulating cell proliferation, migration, invasion, and angiogenesis processes (Valiulyte et al., 2019). FR-Sema3C is a point mutated form of Sema3C that is resistant to cleavage by furin like proprotein convertases, which functions as an anti-angiogenic factor by inhibiting VEGF expression in endothelial cells (Toledano et al., 2016). In the developing cortex, interaction between matrix metalloproteinase- 3 and Sema3C participated in the growth of axons and dendrites (Gonthier et al., 2007). Sema3D, like Sema3E, is capable of inhibiting endothelial cell motility, migration, and tube formation (Aghajanian et al., 2014; Taku et al., 2016). These evidence leads us to conjecture that Sema3C and Sema3D may be associated with vascular permeability and migration of neurons. Semaphorin 3F (Sema3F) modulates the morphology and function of synapses in the adult hippocampus. Mice lacking Sema3F are prone to seizures, suggesting that Sema3F is essential for the normal function of hippocampal circuits (Sahay et al., 2005). Semaphorin 3G (Sema3G) is secreted by the vascular system in the CNS and essential for the control of neural circuit stability and cognitive functions (Carulli et al., 2021). But there has been no direct evidence that Sema3F and Sema3G are associated with ischemic stroke.

Semaphorin 4A (Sema4A), like Sema4D, is immunomodulatory molecules in the immune cells. Sema4A binds to NRP- 1 and promotes $\mathrm{T}$ cell activation and inflammation. In kidney ischemia reperfusion injury model, Sema 4 A alleviates inflammatory reaction by promoting the stability and function of regulatory $\mathrm{T}$ cells (Xu et al., 2021). Regulatory $\mathrm{T}$ cells are closely related to the pathogenesis of ischemic stroke. Semaphorin 4C (Sema4C) and semaphorin $4 \mathrm{G}$ (Sema4G), which are widely expressed in the developing nervous system, promote macrophage recruitment, angiogenesis and inflammatory reaction (Maier et al., 2011). Hence, semaphorin 4 may affect the development of brain ischemia reperfusion injury.

Semaphorin 5 has unique thrombospondin repeats as extracelluar domains. It's well-known that semaphorin $5 \mathrm{~A}$

\section{REFERENCES}

Abdul-Muneer, P. M., Schuetz, H., Wang, F., Skotak, M., Jones, J., Gorantla, S., et al. (2013). Induction of oxidative and nitrosative damage leads to cerebrovascular inflammation in an animal model of mild traumatic brain injury induced by primary blast. Free Radic. Biol. Med. 60, 282-291.

Abe, N., Nishihara, T., Yorozuya, T., and Tanaka, J. (2020). Microglia and macrophages in the pathological central and peripheral nervous systems. Cells 9:e092132. doi: 10.3390/cells9092132
(Sema5A) and its receptors play an important role in the invasion and metastasis of tumor cells by promoting angiogenesis (Sadanandam et al., 2010; Purohit et al., 2014). A study indicated that Sema5A was correlated with Th1 polarization, which increased the production of inflammatory cytokines (Lyu et al., 2015). A Th1-type response is neurotoxic and contributes to the poor outcome of stroke (Korhonen et al., 2015). Semaphorin 5B (Sema5B), as a repulsive guidance cue in the formation of the internal capsule, is expressed in the region of the cortex and subcortex (Lett et al., 2009). Sema5B also suppresses endothelial cell proliferation, migration and sprouting, and plays an important role in the regulation of neovascularization (Grundmann et al., 2013). The above evidence implies thatSema5A and Sema5B may contribute to the progression of vascular diseases such as stroke.

\section{PERSPECTIVES}

Semaphorins are a large and diverse family of proteins involved in different physiological and pathological processes. Emerging evidence indicates that semaphorins not only regulate the shape and motility of neurons, but also relates with glial cell activity, blood-brain barrier (BBB) permeability, angiogenesis and inflammation/immune response in ischemic stroke. In this review, we summarized the role of semaphorins in NVU after stroke. Sema3A, a deeply understood member of the semaphorin family, mainly regulates the functions of neurons, glial cells, vascular system in the NVU. Sema4D and Sema7A signaling mainly participates in inflammatory response in pericytes and microglial cells after stroke. Like Sema3A, Sema3E and Sema4D can bind to their receptors directly on endothelial cells or affects VEGF expression to regulate neovascularization. The major roles of semaphorins in NVU after stroke are list in Table 1. Although there are limitations on the regulation the NVU function through a single semaphorin family member and its signaling pathway to improve functional recovery after ischemic stroke, coordination of the roles of different semaphorin members in the NVU and the successful clinical translational investigation could be potential approaches in prevention and treatment of ischemic stroke.

\section{AUTHOR CONTRIBUTIONS}

HD and YX selected topics. HD wrote the review. LZ reviewed the manuscript and modified the content. All authors contributed to the article and approved the submitted version.

Acevedo, L. M., Barillas, S., Weis, S. M., Gothert, J. R., and Cheresh, D. A. (2008). Semaphorin 3A suppresses VEGF-mediated angiogenesis yet acts as a vascular permeability factor. Blood 111, 2674-2680. doi: 10.1182/blood-2007-08-110205

Aghajanian, H., Choi, C., Ho, V. C., Gupta, M., Singh, M. K., and Epstein, J. A. (2014). Semaphorin 3d and semaphorin 3e direct endothelial motility through distinct molecular signaling pathways. J. Biol. Chem. 289, 17971-17979.

Alvarez-Buylla, A., Seri, B., and Doetsch, F. (2002). Identification of neural stem cells in the adult vertebrate brain. Brain Res. Bull. 57, 751-758. doi: 10.1016/ s0361-9230(01)00770-5 
Amantea, D., Nappi, G., Bernardi, G., Bagetta, G., and Corasaniti, M. T. (2009). Post-ischemic brain damage: pathophysiology and role of inflammatory mediators. FEBS J. 276, 13-26. doi: 10.1111/j.1742-4658.2008.06766.x

Armstead, W. M., and Raghupathi, R. (2011). Endothelin and the neurovascular unit in pediatric traumatic brain injury. Neurol. Res. 33, 127-132. doi: 10.1179/ 016164111 X12881719352138

Arvidsson, A., Collin, T., Kirik, D., Kokaia, Z., and Lindvall, O. (2002). Neuronal replacement from endogenous precursors in the adult brain after stroke. Nat. Med. 8, 963-970. doi: 10.1038/nm747

Aylsworth, A., Jiang, S. X., Desbois, A., and Hou, S. T. (2009). Characterization of the role of full-length CRMP3 and its calpain-cleaved product in inhibiting microtubule polymerization and neurite outgrowth. Exp. Cell Res. 315, 28562868. doi: 10.1016/j.yexcr.2009.06.014

Banerjee, S., and Bhat, M. A. (2007). Neuron-glial interactions in blood-brain barrier formation. Annu. Rev. Neurosci. 30, 235-258. doi: 10.1146/annurev. neuro.30.051606.094345

Beck, H., Acker, T., Puschel, A. W., Fujisawa, H., Carmeliet, P., and Plate, K. H. (2002). Cell type-specific expression of neuropilins in an MCA-occlusion model in mice suggests a potential role in post-ischemic brain remodeling. J. Neuropathol. Exp. Neurol. 61, 339-350. doi: 10.1093/jnen/61.4.339

Ben-Gigi, L., Sweetat, S., Besser, E., Fellig, Y., Wiederhold, T., Polakiewicz, R. D., et al. (2015). Astrogliosis induced by brain injury is regulated by Sema4B phosphorylation. eNeuro 2:ENEURO.0078-14.2015. doi: 10.1523/ENEURO. 0078-14.2015

Bernardo-Castro, S., Sousa, J. A., Bras, A., Cecilia, C., Rodrigues, B., Almendra, L., et al. (2020). Pathophysiology of Blood-Brain barrier permeability throughout the different stages of ischemic stroke and its implication on hemorrhagic transformation and recovery. Front. Neurol. 11:594672. doi: 10.3389/fneur. 2020.594672

Bijian, K., Takano, T., Papillon, J., Le Berre, L., Michaud, J. L., Kennedy, C. R., et al. (2005). Actin cytoskeleton regulates extracellular matrix-dependent survival signals in glomerular epithelial cells. Am. J. Physiol. Renal Physiol. 289, F1313F1323. doi: 10.1152/ajprenal.00106.2005

Boese, A. C., Lee, J. P., and Hamblin, M. H. (2020). Neurovascular protection by peroxisome proliferator-activated receptor alpha in ischemic stroke. Exp. Neurol. 331:113323. doi: 10.1016/j.expneurol.2020.113323

Carulli, D., de Winter, F., and Verhaagen, J. (2021). Semaphorins in adult nervous system plasticity and disease. Front. Synap. Neurosci. 13:672891. doi: 10.3389/ fnsyn.2021.672891

Casazza, A., Fu, X., Johansson, I., Capparuccia, L., Andersson, F., Giustacchini, A., et al. (2011). Systemic and targeted delivery of semaphorin $3 \mathrm{~A}$ inhibits tumor angiogenesis and progression in mouse tumor models. Arterioscler. Thromb. Vasc. Biol. 31, 741-749. doi: 10.1161/ATVBAHA.110.2 11920

Choudhury, G. R., and Ding, S. (2016). Reactive astrocytes and therapeutic potential in focal ischemic stroke. Neurobiol. Dis. 85, 234-244. doi: 10.1016/j. nbd.2015.05.003

Collet, P., Domenjoud, L., Devignes, M. D., Murad, H., Schohn, H., and Dauca, M. (2004). The human semaphorin 6B gene is down regulated by PPARs. Genomics 83, 1141-1150. doi: 10.1016/j.ygeno.2004.01.002

Conrotto, P., Valdembri, D., Corso, S., Serini, G., Tamagnone, L., Comoglio, P. M., et al. (2005). Sema4D induces angiogenesis through Met recruitment by Plexin B1. Blood 105, 4321-4329. doi: 10.1182/blood-2004-07-2885

Correa, R. G., Sasahara, R. M., Bengtson, M. H., Katayama, M. L., Salim, A. C., Brentani, M. M., et al. (2001). Human semaphorin 6B [(HSA)SEMA6B], a novel human class 6 semaphorin gene: alternative splicing and all-trans-retinoic aciddependent downregulation in glioblastoma cell lines. Genomics 73, 343-348. doi: 10.1006/geno.2001.6525

Cunnane, S. C., Trushina, E., Morland, C., Prigione, A., Casadesus, G., Andrews, Z. B., et al. (2020). Brain energy rescue: an emerging therapeutic concept for neurodegenerative disorders of ageing. Nat. Rev. Drug Discov. 19, 609-633. doi: 10.1038/s41573-020-0072-x

Datta, A., Sarmah, D., Mounica, L., Kaur, H., Kesharwani, R., Verma, G., et al. (2020). Cell death pathways in ischemic stroke and targeted pharmacotherapy. Transl. Stroke Res. 11, 1185-1202. doi: 10.1007/s12975-020-00806-z

Davis, C., Savitz, S. I., and Satani, N. (2021). Mesenchymal stem cell derived extracellular vesicles for repairing the neurovascular unit after ischemic stroke. Cells 10:767. doi: 10.3390/cells10040767
Dienel, G. A., and Hertz, L. (2001). Glucose and lactate metabolism during brain activation. J. Neurosci. Res. 66, 824-838. doi: 10.1002/jnr.10079

Ding, J. B., Oh, W. J., Sabatini, B. L., and Gu, C. (2011). Semaphorin 3E-PlexinD1 signaling controls pathway-specific synapse formation in the striatum. Nat. Neurosci. 15, 215-223. doi: 10.1038/nn.3003

Dore-Duffy, P., Balabanov, R., Beaumont, T., and Katar, M. (2005). The CNS pericyte response to low oxygen: early synthesis of cyclopentenone prostaglandins of the J-series. Microvasc. Res. 69, 79-88. doi: 10.1016/j.mvr. 2004.11.004

Duchemin, S., Boily, M., Sadekova, N., and Girouard, H. (2012). The complex contribution of NOS interneurons in the physiology of cerebrovascular regulation. Front. Neural Circ. 6:51. doi: 10.3389/fncir.2012.00051

Duz, B., Oztas, E., Erginay, T., Erdogan, E., and Gonul, E. (2007). The effect of moderate hypothermia in acute ischemic stroke on pericyte migration: an ultrastructural study. Cryobiology 55, 279-284. doi: 10.1016/j.cryobiol.2007.08. 009

Fujita, H., Zhang, B., Sato, K., Tanaka, J., and Sakanaka, M. (2001). Expressions of neuropilin-1, neuropilin-2 and semaphorin 3A mRNA in the rat brain after middle cerebral artery occlusion. Brain Res. 914, 1-14. doi: 10.1016/s00068993(01)02765-2

Gavard, J. (2009). Breaking the VE-cadherin bonds. FEBS Lett. 583, 1-6. doi: 10.1016/j.febslet.2008.11.032

Gengatharan, A., Malvaut, S., Marymonchyk, A., Ghareghani, M., Snapyan, M., Fischer-Sternjak, J., et al. (2021). Adult neural stem cell activation in mice is regulated by the day/night cycle and intracellular calcium dynamics. Cell 184, 709-722. doi: 10.1016/j.cell.2020.12.026

Giacobini, P., Parkash, J., Campagne, C., Messina, A., Casoni, F., Vanacker, C., et al. (2014). Brain endothelial cells control fertility through ovarian-steroiddependent release of semaphorin 3A. PLoS Biol. 12:e1001808. doi: 10.1371/ journal.pbio. 1001808

Giese, A., Schirmer, M. D., Dalca, A. V., Sridharan, R., Donahue, K. L., Nardin, M., et al. (2020). White matter hyperintensity burden in acute stroke patients differs by ischemic stroke subtype. Neurology 95, e79-e88. doi: 10.1212/WNL. 0000000000009728

Gonthier, B., Nasarre, C., Roth, L., Perraut, M., Thomasset, N., Roussel, G., et al. (2007). Functional interaction between matrix metalloproteinase-3 and semaphorin-3C during cortical axonal growth and guidance. Cereb. Cortex 17, 1712-1721. doi: 10.1093/cercor/bhl082

Gordon, G. R., Choi, H. B., Rungta, R. L., Ellis-Davies, G. C., and MacVicar, B. A. (2008). Brain metabolism dictates the polarity of astrocyte control over arterioles. Nature 456, 745-749. doi: 10.1038/nature07525

Grundmann, S., Lindmayer, C., Hans, F. P., Hoefer, I., Helbing, T., Pasterkamp, G., et al. (2013). FoxP1 stimulates angiogenesis by repressing the inhibitory guidance protein semaphorin 5B in endothelial cells. PLoS One 8:e70873. doi: 10.1371/journal.pone.0070873

Gutierrez-Franco, A., Eixarch, H., Costa, C., Gil, V., Castillo, M., Calvo-Barreiro, L., et al. (2017). Semaphorin 7A as a potential therapeutic target for multiple sclerosis. Mol. Neurobiol. 54, 4820-4831. doi: 10.1007/s12035-016-0154-2

Hartle, K. D., Jeffers, M. S., and Ivanco, T. L. (2010). Changes in dendritic morphology and spine density in motor cortex of the adult rat after stroke during infancy. Synapse 64, 602-610. doi: 10.1002/syn .20767

Hashimoto, M., Ino, H., Koda, M., Murakami, M., Yoshinaga, K., Yamazaki, M., et al. (2004). Regulation of semaphorin 3A expression in neurons of the rat spinal cord and cerebral cortex after transection injury. Acta Neuropathol. 107, 250-256. doi: 10.1007/s00401-003-0805-Z

Hatanaka, Y., Kawasaki, T., Abe, T., Shioi, G., Kohno, T., Hattori, M., et al. (2019). Semaphorin 6A-Plexin A2/A4 interactions with radial glia regulate migration termination of superficial layer cortical neurons. iScience 21, 359-374. doi: 10.1016/j.isci.2019.10.034

He, Y., Yang, Y., Wang, R., Wang, H., Ma, Q., Chen, S., et al. (2018). Expression changes and roles of Sema3A and Nrp1 in cultured rat cortical neurons after oxygen glucose deprivation. Cell Mol. Biol. 64, 64-69.

Heemskerk, N., van Rijssel, J., and van Buul, J. D. (2014). Rho-GTPase signaling in leukocyte extravasation: an endothelial point of view. Cell Adh. Migr. 8, 67-75. doi: $10.4161 /$ cam. 28244

Hess, D. L., Kelly-Goss, M. R., Cherepanova, O. A., Nguyen, A. T., Baylis, R. A., Tkachenko, S., et al. (2019). Perivascular cell-specific knockout of the stem 
cell pluripotency gene Oct4 inhibits angiogenesis. Nat. Commun. 10:967. doi: 10.1038/s41467-019-08811-z

Hira, K., Ueno, Y., Tanaka, R., Miyamoto, N., Yamashiro, K., Inaba, T., et al. (2018). Astrocyte-derived exosomes treated with a semaphorin 3A inhibitor enhance stroke recovery via prostaglandin d2 synthase. Stroke 49, 2483-2494. doi: 10.1161/STROKEAHA.118.021272

Hou, S. T., Jiang, S. X., Aylsworth, A., Ferguson, G., Slinn, J., Hu, H., et al. (2009). CaMKII phosphorylates collapsin response mediator protein 2 and modulates axonal damage during glutamate excitotoxicity. J. Neurochem. 111, 870-881. doi: 10.1111/j.1471-4159.2009.06375.x

Hou, S. T., Jiang, S. X., Slinn, J., O’Hare, M., and Karchewski, L. (2010). Neuropilin 2 deficiency does not affect cortical neuronal viability in response to oxygenglucose-deprivation and transient middle cerebral artery occlusion. Neurosci. Res. 66, 396-401. doi: 10.1016/j.neures.2009.12.010

Hou, S. T., Keklikian, A., Slinn, J., O'Hare, M., Jiang, S. X., and Aylsworth, A. (2008). Sustained up-regulation of semaphorin 3A, Neuropilin1, and doublecortin expression in ischemic mouse brain during long-term recovery. Biochem. Biophys. Res. Commun. 367, 109-115. doi: 10.1016/j.bbrc.2007.12.103

Hou, S. T., and MacManus, J. P. (2002). Molecular mechanisms of cerebral ischemia-induced neuronal death. Int. Rev. Cytol. 221, 93-148. doi: 10.1016/ s0074-7696(02)21011-6

Hou, S. T., Nilchi, L., Li, X., Gangaraju, S., Jiang, S. X., Aylsworth, A., et al. (2015). Semaphorin3A elevates vascular permeability and contributes to cerebral ischemia-induced brain damage. Sci. Rep. 5:7890. doi: 10.1038/srep07890

Hu, S., Liu, Y., You, T., Heath, J., Xu, L., Zheng, X., et al. (2018a). Vascular semaphorin 7A upregulation by disturbed flow promotes atherosclerosis through endothelial betal integrin. Arterioscler. Thromb. Vasc. Biol. 38, 335343. doi: 10.1161/ATVBAHA.117.310491

Hu, S., Liu, Y., You, T., and Zhu, L. (2018b). Semaphorin 7A promotes VEGFA/VEGFR2-Mediated angiogenesis and intraplaque neovascularization in ApoE(-/-) mice. Front. Physiol. 9:1718. doi: 10.3389/fphys.2018.01718

$\mathrm{Hu}, \mathrm{S}$., and Zhu, L. (2018). Semaphorins and their receptors: from axonal guidance to atherosclerosis. Front. Physiol. 9:1236. doi: 10.3389/fphys.2018.01236

Huang, S. Y., Chang, C. H., Hung, H. Y., Lin, Y. W., and Lee, E. J. (2018). Neuroanatomical and electrophysiological recovery in the contralateral intact cortex following transient focal cerebral ischemia in rats. Neurol. Res. 40, 130-138. doi: 10.1080/01616412.2017.1411454

Iadecola, C. (2017). The neurovascular unit coming of age: a journey through neurovascular coupling in health and disease. Neuron 96, 17-42. doi: 10.1016/j. neuron.2017.07.030

Inoue, M., Chen, P. H., Siecinski, S., Li, Q. J., Liu, C., Steinman, L., et al. (2016). An interferon-beta-resistant and NLRP3 inflammasome-independent subtype of EAE with neuronal damage. Nat. Neurosci. 19, 1599-1609. doi: 10.1038/nn.4421

Jha, M. K., Kim, J. H., Song, G. J., Lee, W. H., Lee, I. K., Lee, H. W., et al. (2018). Functional dissection of astrocyte-secreted proteins: implications in brain health and diseases. Prog. Neurobiol. 162, 37-69. doi: 10.1016/j.pneurobio. 2017.12.003

Jiang, S. X., Sheldrick, M., Desbois, A., Slinn, J., and Hou, S. T. (2007). Neuropilin-1 is a direct target of the transcription factor E2F1 during cerebral ischemiainduced neuronal death in vivo. Mol. Cell. Biol. 27, 1696-1705. doi: 10.1128/ MCB.01760-06

Jiang, S. X., Whitehead, S., Aylsworth, A., Slinn, J., Zurakowski, B., Chan, K., et al. (2010). Neuropilin 1 directly interacts with Fer kinase to mediate semaphorin 3A-induced death of cortical neurons. J. Biol. Chem. 285, 9908-9918. doi: 10. 1074/jbc.M109.080689

Jiang, X., Andjelkovic, A. V., Zhu, L., Yang, T., Bennett, M., Chen, J., et al. (2018). Blood-brain barrier dysfunction and recovery after ischemic stroke. Prog. Neurobiol. 163-164, 144-171. doi: 10.1016/j.pneurobio.2017.10.001

Jongbloets, B. C., Lemstra, S., Schellino, R., Broekhoven, M. H., Parkash, J., Hellemons, A. J., et al. (2017). Stage-specific functions of Semaphorin7A during adult hippocampal neurogenesis rely on distinct receptors. Nat. Commun. 8:14666. doi: $10.1038 /$ ncomms 14666

Junqueira, A. C., Dariolli, R., Haydak, J., Kang, S., Hannah, T., Wiener, R. J., et al. (2021). Plexin-B2 orchestrates collective stem cell dynamics via actomyosin contractility, cytoskeletal tension and adhesion. Nat. Commun. 12:6019. doi: 10.1038/s41467-021-26296-7

Kaneko, S., Iwanami, A., Nakamura, M., Kishino, A., Kikuchi, K., Shibata, S., et al. (2006). A selective Sema3A inhibitor enhances regenerative responses and functional recovery of the injured spinal cord. Nat. Med. 12, 1380-1389. doi: $10.1038 / \mathrm{nm} 1505$

Keyvani, K., and Schallert, T. (2002). Plasticity-associated molecular and structural events in the injured brain. J. Neuropathol. Exp. Neurol. 61, 831-840. doi: 10.1093/jnen/61.10.831

Khoshnam, S. E., Winlow, W., Farzaneh, M., Farbood, Y., and Moghaddam, H. F. (2017). Pathogenic mechanisms following ischemic stroke. Neurol. Sci. 38, 1167-1186. doi: 10.1007/s10072-017-2938-1

Kigel, B., Rabinowicz, N., Varshavsky, A., Kessler, O., and Neufeld, G. (2011). Plexin-A4 promotes tumor progression and tumor angiogenesis by enhancement of VEGF and bFGF signaling. Blood 118, 4285-4296. doi: 10. 1182/blood-2011-03-341388

Ko, K., Suzuki, T., Ishikawa, R., Hattori, N., Ito, R., Umehara, K., et al. (2020). Ischemic stroke disrupts the endothelial glycocalyx through activation of proHPSE via acrolein exposure. J. Biol. Chem. 295, 18614-18624. doi: 10.1074/ jbc.RA120.015105

Kolodkin, A. L., Matthes, D. J., and Goodman, C. S. (1993). The semaphorin genes encode a family of transmembrane and secreted growth cone guidance molecules. Cell 75, 1389-1399. doi: 10.1016/0092-8674(93)90625-z

Korhonen, P., Kanninen, K. M., Lehtonen, S., Lemarchant, S., Puttonen, K. A., Oksanen, M., et al. (2015). Immunomodulation by interleukin-33 is protective in stroke through modulation of inflammation. Brain Behav. Immun. 49, 322-336. doi: 10.1016/j.bbi.2015.06.013

Krueger, M., Bechmann, I., Immig, K., Reichenbach, A., Hartig, W., and Michalski, D. (2015). Blood-brain barrier breakdown involves four distinct stages of vascular damage in various models of experimental focal cerebral ischemia. J. Cereb. Blood Flow Metab. 35, 292-303. doi: 10.1038/jcbfm.2014.199

Kruger, C., Cira, D., Sommer, C., Fischer, A., Schabitz, W. R., and Schneider, A. (2006). Long-term gene expression changes in the cortex following cortical ischemia revealed by transcriptional profiling. Exp. Neurol. 200, 135-152. doi: 10.1016/j.expneurol.2006.01.025

Le Guelte, A., Galan-Moya, E. M., Dwyer, J., Treps, L., Kettler, G., Hebda, J. K., et al. (2012). Semaphorin 3A elevates endothelial cell permeability through PP2A inactivation. J. Cell Sci. 125(Pt 17), 4137-4146. doi: 10.1242/jcs.10 8282

Lett, R. L., Wang, W., and O'Connor, T. P. (2009). Semaphorin 5B is a novel inhibitory cue for corticofugal axons. Cereb. Cortex 19, 1408-1421. doi: 10. 1093/cercor/bhn179

Li, Q., and Barres, B. A. (2018). Microglia and macrophages in brain homeostasis and disease. Nat. Rev. Immunol. 18, 225-242. doi: 10.1038/nri.2017.125

Limoni, G. (2021). Modelling and refining neuronal circuits with guidance cues: involvement of semaphorins. Int. J. Mol. Sci. 22:6111. doi: 10.3390/ ijms 22116111

Limoni, G., and Niquille, M. (2021). Semaphorins and Plexins in central nervous system patterning: the key to it all? Curr. Opin. Neurobiol. 66, 224-232. doi: 10.1016/j.conb.2020.12.014

Lin, W., and Powers, W. J. (2018). Oxygen metabolism in acute ischemic stroke. J. Cereb. Blood Flow Metab. 38, 1481-1499. doi: 10.1177/0271678X17722095

Liu, L. R., Liu, J. C., Bao, J. S., Bai, Q. Q., and Wang, G. Q. (2020). Interaction of microglia and astrocytes in the neurovascular unit. Front. Immunol. 11:1024. doi: 10.3389/fimmu.2020.01024

Liu, X., Liu, J., Zhao, S., Zhang, H., Cai, W., Cai, M., et al. (2016). Interleukin-4 is essential for Microglia/Macrophage $\mathrm{m} 2$ polarization and Long-Term recovery after cerebral ischemia. Stroke 47, 498-504. doi: 10.1161/STROKEAHA.115. 012079

Lopez-Bayghen, E., and Ortega, A. (2011). Glial glutamate transporters: new actors in brain signaling. Iubmb Life 63, 816-823. doi: 10.1002/iub.536

Lu, Q., and Zhu, L. (2020). The role of semaphorins in metabolic disorders. Int. J. Mol. Sci. 21:5641. doi: 10.3390/ijms21165641

Luo, Y., Raible, D., and Raper, J. A. (1993). Collapsin: a protein in brain that induces the collapse and paralysis of neuronal growth cones. Cell 75, 217-227. doi: 10.1016/0092-8674(93)80064-1

Luque, M. C., Gutierrez, P. S., Debbas, V., Kalil, J., and Stolf, B. S. (2015). CD100 and plexins B2 and B1 mediate monocyte-endothelial cell adhesion and might take part in atherogenesis. Mol. Immunol. 67(2 Pt B), 559-567. doi: 10.1016/j. molimm.2015.07.028

Lyu, M., Li, Y., Hao, Y., Sun, T., Liu, W., Lyu, C., et al. (2015). Elevated Semaphorin $5 \mathrm{~A}$ correlated with Th1 polarization in patients with chronic immune 
thrombocytopenia. Thromb. Res. 136, 859-864. doi: 10.1016/j.thromres.2015. 07.032

MacKeigan, D. T., Ni, T., Shen, C., Stratton, T. W., Ma, W., Zhu, G., et al. (2020). Updated understanding of platelets in thrombosis and hemostasis: the roles of integrin PSI domains and their potential as therapeutic targets. Cardiovasc. Hematol. Disord. Drug Targets 20, 260-273. doi: 10.2174/ 1871529X20666201001144541

Maier, V., Jolicoeur, C., Rayburn, H., Takegahara, N., Kumanogoh, A., Kikutani, H., et al. (2011). Semaphorin $4 \mathrm{C}$ and $4 \mathrm{G}$ are ligands of Plexin-B2 required in cerebellar development. Mol. Cell. Neurosci. 46, 419-431. doi: 10.1016/j.mcn. 2010.11.005

Makihara, H., Nakai, S., Ohkubo, W., Yamashita, N., Nakamura, F., Kiyonari, H., et al. (2016). CRMP1 and CRMP2 have synergistic but distinct roles in dendritic development. Genes Cells 21, 994-1005. doi: 10.1111/gtc.12399

Mohan, V., Wade, S. D., Sullivan, C. S., Kasten, M. R., Sweetman, C., Stewart, R., et al. (2019). Close homolog of 11 regulates dendritic spine density in the mouse cerebral cortex through semaphorin 3B. J. Neurosci. 39, 6233-6250. doi: 10.1523/JNEUROSCI.2984-18.2019

Mohan, V., Wyatt, E. V., Gotthard, I., Phend, K. D., Diestel, S., Duncan, B. W., et al. (2018). Neurocan inhibits semaphorin 3F induced dendritic spine remodeling through NrCAM in cortical neurons. Front. Cell. Neurosci. 12:346. doi: 10.3389/ fncel.2018.00346

Moreau-Fauvarque, C., Kumanogoh, A., Camand, E., Jaillard, C., Barbin, G., Boquet, I., et al. (2003). The transmembrane semaphorin Sema4D/CD100, an inhibitor of axonal growth, is expressed on oligodendrocytes and upregulated after CNS lesion. J. Neurosci. 23, 9229-9239. doi: 10.1523/JNEUROSCI.23-2709229.2003

Moreno, P. R. (2001). Pathophysiology of plaque disruption and thrombosis in acute ischemic syndromes. J. Stroke Cerebrovasc. Dis. $10(2 \mathrm{Pt} 2), 2-9$. doi: 10.1053/jscd.2001.24785

Morote-Garcia, J. C., Napiwotzky, D., Kohler, D., and Rosenberger, P. (2012). Endothelial Semaphorin 7A promotes neutrophil migration during hypoxia. Proc. Natl. Acad. Sci. U.S.A. 109, 14146-14151. doi: 10.1073/pnas.1202165109

Nakagawa, Y., Takamatsu, H., Okuno, T., Kang, S., Nojima, S., Kimura, T., et al. (2011). Identification of semaphorin $4 \mathrm{~B}$ as a negative regulator of basophil-mediated immune responses. J. Immunol. 186, 2881-2888. doi: 10. 4049/jimmunol.1003485

Nakamura, F., Kalb, R. G., and Strittmatter, S. M. (2000). Molecular basis of semaphorin-mediated axon guidance. J. Neurobiol. 44, 219-229.

Nakamura, H., Takahashi-Jitsuki, A., Makihara, H., Asano, T., Kimura, Y., Nakabayashi, J., et al. (2018). Proteome and behavioral alterations in phosphorylation-deficient mutant Collapsin Response Mediator Protein2 knock-in mice. Neurochem. Int. 119, 207-217. doi: 10.1016/j.neuint.2018.04.009

Nissen, J. C., and Tsirka, S. E. (2016). Tuftsin-driven experimental autoimmune encephalomyelitis recovery requires neuropilin-1. Glia 64, 923-936. doi: 10. 1002/glia.22972

Oh, W. J., and Gu, C. (2013). The role and mechanism-of-action of Sema3E and Plexin-D1 in vascular and neural development. Semin. Cell Dev. Biol. 24, 156-162. doi: 10.1016/j.semcdb.2012.12.001

Okada, T., Keino-Masu, K., Suto, F., Mitchell, K. J., and Masu, M. (2019). Remarkable complexity and variability of corticospinal tract defects in adult Semaphorin 6A knockout mice. Brain Res. 1710, 209-219. doi: 10.1016/j. brainres.2018.12.041

Okuno, T., Nakatsuji, Y., Moriya, M., Takamatsu, H., Nojima, S., Takegahara, N., et al. (2010). Roles of Sema4D-plexin-B1 interactions in the central nervous system for pathogenesis of experimental autoimmune encephalomyelitis. J. Immunol. 184, 1499-1506. doi: 10.4049/jimmunol.0903302

Pasterkamp, R. J., Peschon, J. J., Spriggs, M. K., and Kolodkin, A. L. (2003). Semaphorin 7A promotes axon outgrowth through integrins and MAPKs. Nature 424, 398-405. doi: 10.1038/nature01790

Pekcec, A., Yigitkanli, K., Jung, J. E., Pallast, S., Xing, C., Antipenko, A., et al. (2013). Following experimental stroke, the recovering brain is vulnerable to lipoxygenase-dependent semaphorin signaling. FASEB J. 27, 437-445. doi: 10. 1096/fj.12-206896

Perrotta, P., de Vries, M. R., Peeters, B., Guns, P. J., De Meyer, G., Quax, P., et al. (2021). PFKFB3 gene deletion in endothelial cells inhibits intraplaque angiogenesis and lesion formation in a murine model of venous bypass grafting. Angiogenesis 25, 129-143. doi: 10.1007/s10456-021-09816-3
Poyhonen, S., Er, S., Domanskyi, A., and Airavaara, M. (2019). Effects of neurotrophic factors in glial cells in the central nervous system: expression and properties in neurodegeneration and injury. Front. Physiol. 10:486. doi: 10.3389/fphys.2019.00486

Pratte, M., Rougon, G., Schachner, M., and Jamon, M. (2003). Mice deficient for the close homologue of the neural adhesion cell L1 (CHL1) display alterations in emotional reactivity and motor coordination. Behav. Brain Res. 147, 31-39. doi: 10.1016/s0166-4328(03)00114-1

Purohit, A., Sadanandam, A., Myneni, P., and Singh, R. K. (2014). Semaphorin 5A mediated cellular navigation: connecting nervous system and cancer. Biochim. Biophys. Acta 1846, 485-493. doi: 10.1016/j.bbcan.2014. 09.006

Qin, C., Zhou, L. Q., Ma, X. T., Hu, Z. W., Yang, S., Chen, M., et al. (2019). Dual functions of microglia in ischemic stroke. Neurosci. Bull. 35, 921-933. doi: 10.1007/s12264-019-00388-3

Rahman, A. A., Amruta, N., Pinteaux, E., and Bix, G. J. (2021). Neurogenesis after stroke: a therapeutic perspective. Transl. Stroke Res. 12, 1-14. doi: 10.1007/ s12975-020-00841-w

Raper, J. A. (2000). Semaphorins and their receptors in vertebrates and invertebrates. Curr. Opin. Neurobiol. 10, 88-94. doi: 10.1016/s0959-4388(99) 00057-4

Rivera, J. C., Sitaras, N., Noueihed, B., Hamel, D., Madaan, A., Zhou, T., et al. (2013). Microglia and interleukin-1beta in ischemic retinopathy elicit microvascular degeneration through neuronal semaphorin-3A. Arterioscler. Thromb. Vasc. Biol. 33, 1881-1891. doi: 10.1161/ATVBAHA.113.3 01331

Rogalewski, A., Dittgen, T., Klugmann, M., Kirsch, F., Kruger, C., Pitzer, C., et al. (2010). Semaphorin 6A improves functional recovery in conjunction with motor training after cerebral ischemia. PLoS One 5:e10737. doi: 10.1371/ journal.pone.0010737

Sadanandam, A., Rosenbaugh, E. G., Singh, S., Varney, M., and Singh, R. K. (2010). Semaphorin 5A promotes angiogenesis by increasing endothelial cell proliferation, migration, and decreasing apoptosis. Microvasc. Res. 79, 1-9. doi: 10.1016/j.mvr.2009.10.005

Sahay, A., Kim, C. H., Sepkuty, J. P., Cho, E., Huganir, R. L., Ginty, D. D., et al. (2005). Secreted semaphorins modulate synaptic transmission in the adult hippocampus. J. Neurosci. 25, 3613-3620. doi: 10.1523/JNEUROSCI.5255-04. 2005

Santopolo, G., Magnusson, J. P., Lindvall, O., Kokaia, Z., and Frisen, J. (2020). Blocking notch-signaling increases neurogenesis in the striatum after stroke. Cells 9:1732. doi: 10.3390/cells9071732

Sarikaya, H., Ferro, J., and Arnold, M. (2015). Stroke prevention-medical and lifestyle measures. Eur. Neurol. 73, 150-157. doi: 10.1159/00036 7652

Sawano, T., Tsuchihashi, R., Watanabe, F., Niimi, K., Yamaguchi, W., Yamaguchi, N., et al. (2019). Changes in L-arginine metabolism by Sema4D deficiency induce promotion of microglial proliferation in ischemic cortex. Neuroscience 406, 420-431. doi: 10.1016/j.neuroscience.2019.03.037

Sawano, T., Watanabe, F., Ishiguchi, M., Doe, N., Furuyama, T., and Inagaki, S. (2015). Effect of Sema4D on microglial function in middle cerebral artery occlusion mice. Glia 63, 2249-2259. doi: 10.1002/glia.22890

Schwarz, Q., Maden, C. H., Vieira, J. M., and Ruhrberg, C. (2009). Neuropilin 1 signaling guides neural crest cells to coordinate pathway choice with cell specification. Proc. Natl. Acad. Sci. U.S.A. 106, 6164-6169. doi: 10.1073/pnas. 0811521106

Segarra, M., Ohnuki, H., Maric, D., Salvucci, O., Hou, X., Kumar, A., et al. (2012). Semaphorin 6A regulates angiogenesis by modulating VEGF signaling. Blood 120, 4104-4115. doi: 10.1182/blood-2012-02-4 10076

Sekerdag, E., Solaroglu, I., and Gursoy-Ozdemir, Y. (2018). Cell death mechanisms in stroke and novel molecular and cellular treatment options. Curr. Neuropharmacol. 16, 1396-1415. doi: 10.2174/1570159X166661803021 15544

Song, X., Meng, J., Yan, G., Wang, H., Li, H., and Lou, D. (2021). Semaphorin 7A knockdown improves injury and prevents endothelialto-mesenchymal transition in ox-LDL-induced HUVECs by regulating beta1 integrin expression. Exp. Ther. Med. 22:1441. doi: 10.3892/etm.2021. 10876 
Steliga, A., Kowianski, P., Czuba, E., Waskow, M., Morys, J., and Lietzau, G. (2020). Neurovascular unit as a source of ischemic stroke Biomarkers-Limitations of experimental studies and perspectives for clinical application. Transl. Stroke Res. 11, 553-579. doi: 10.1007/s12975-019-00744-5

Takahashi, T., Fournier, A., Nakamura, F., Wang, L. H., Murakami, Y., Kalb, R. G., et al. (1999). Plexin-neuropilin-1 complexes form functional semaphorin-3A receptors. Cell 99, 59-69. doi: 10.1016/s0092-8674(00)80062-8

Taku, A. A., Marcaccio, C. L., Ye, W., Krause, G. J., and Raper, J. A. (2016). Attractant and repellent cues cooperate in guiding a subset of olfactory sensory axons to a well-defined protoglomerular target. Development 143, 123-132. doi: 10.1242/dev.127985

Tao, T., Liu, M., Chen, M., Luo, Y., Wang, C., Xu, T., et al. (2020). Natural medicine in neuroprotection for ischemic stroke: challenges and prospective. Pharmacol. Ther. 216:107695. doi: 10.1016/j.pharmthera.2020.107695

Tasca, C. I., Dal-Cim, T., and Cimarosti, H. (2015). In vitro oxygen-glucose deprivation to study ischemic cell death. Methods Mol. Biol. 1254, 197-210. doi: 10.1007/978-1-4939-2152-2_15

Taupin, P., and Gage, F. H. (2002). Adult neurogenesis and neural stem cells of the central nervous system in mammals. J. Neurosci. Res. 69, 745-749. doi: 10.1002/jnr.10378

Taylor, S. L., Trudeau, D., Arnold, B., Wang, J., Gerrow, K., Summerfeldt, K., et al. (2015). VEGF can protect against blood brain barrier dysfunction, dendritic spine loss and spatial memory impairment in an experimental model of diabetes. Neurobiol. Dis. 78, 1-11. doi: 10.1016/j.nbd.2015.03.022

Tian, L., Rauvala, H., and Gahmberg, C. G. (2009). Neuronal regulation of immune responses in the central nervous system. Trends Immunol. 30, 91-99. doi: 10. 1016/j.it.2008.11.002

Toguchi, M., Gonzalez, D., Furukawa, S., and Inagaki, S. (2009). Involvement of Sema4D in the control of microglia activation. Neurochem. Int. 55, 573-580. doi: 10.1016/j.neuint.2009.05.013

Toledano, S., Lu, H., Palacio, A., Ziv, K., Kessler, O., Schaal, S., et al. (2016). A Sema3C mutant resistant to cleavage by furin (FR-Sema3C) inhibits choroidal neovascularization. PLoS One 11:e168122. doi: 10.1371/journal.pone.0168122

Treps, L., and Gavard, J. (2017). Assaying the action of secreted semaphorins on vascular permeability. Methods Mol. Biol. 1493, 417-427. doi: 10.1007/978-14939-6448-2_30

Tsai, C. F., Thomas, B., and Sudlow, C. L. (2013). Epidemiology of stroke and its subtypes in Chinese vs white populations: a systematic review. Neurology 81, 264-272. doi: 10.1212/WNL.0b013e31829bfde3

Tsuchihashi, R., Sawano, T., Watanabe, F., Yamaguchi, N., Yamaguchi, W., Niimi, K., et al. (2020). Upregulation of IFN-beta induced by Sema4D-dependent partial Erk1/2 inhibition promotes NO production in microglia. Biochem. Biophys. Res. Commun. 521, 827-832. doi: 10.1016/j.bbrc.2019.10.201

Valiulyte, I., Curkunaviciute, R., Ribokaite, L., Kazlauskas, A., Vaitkeviciute, M., Skauminas, K., et al. (2019). The Anti-Tumorigenic activity of Sema3C in the chick embryo chorioallantoic membrane model. Int. J. Mol. Sci. 20:5672. doi: $10.3390 /$ ijms 20225672

Vecera, J., Prochazkova, J., Sumberova, V., Panska, V., Paculova, H., Lanova, M. K., et al. (2020). Hypoxia/Hiflalpha prevents premature neuronal differentiation of neural stem cells through the activation of Hes1. Stem Cell Res. 45:101770. doi: 10.1016/j.scr.2020.101770

Vieira, J. M., Schwarz, Q., and Ruhrberg, C. (2007). Role of the neuropilin ligands VEGF164 and SEMA3A in neuronal and vascular patterning in the mouse. Novartis Found Symp. 283, 235-241. doi: 10.1002/9780470319413.ch18

Wada, T., Sawano, T., Tanaka, T., Furuyama, T., Fukumoto, M., Yamaguchi, W., et al. (2016). Absence of Sema4D improves oligodendrocyte recovery after cerebral ischemia/reperfusion injury in mice. Neurosci. Res. 108, 6-11. doi: 10.1016/j.neures.2015.12.016

Wang, L., Xiong, X., Zhang, L., and Shen, J. (2021). Neurovascular unit: a critical role in ischemic stroke. CNS Neurosci. Ther. 27, 7-16. doi: 10.1111/cns.13561

Wanrooy, B. J., Wen, S. W., and Wong, C. H. (2021). Dynamic roles of neutrophils in post-stroke neuroinflammation. Immunol. Cell Biol. 99, 924-935. doi: 10. 1111 /imcb. 12463

Wanschel, A., Seibert, T., Hewing, B., Ramkhelawon, B., Ray, T. D., van Gils, J. M., et al. (2013). Neuroimmune guidance cue Semaphorin 3E is expressed in atherosclerotic plaques and regulates macrophage retention. Arterioscler. Thromb. Vasc. Biol. 33, 886-893. doi: 10.1161/ATVBAHA.112.300941
Wei, Y., Gong, J., Xu, Z., Thimmulappa, R. K., Mitchell, K. L., Welsbie, D. S., et al. (2015). Nrf2 in ischemic neurons promotes retinal vascular regeneration through regulation of semaphorin 6A. Proc. Natl. Acad. Sci. U.S.A. 112, E6927E6936. doi: 10.1073/pnas.1512683112

Whitehead, S. N., Gangaraju, S., Slinn, J., and Hou, S. T. (2010). Transient and bilateral increase in Neuropilin-1, Fer kinase and collapsin response mediator proteins within membrane rafts following unilateral occlusion of the middle cerebral artery in mouse. Brain Res. 1344, 209-216. doi: 10.1016/j.brainres.2010. 05.036

Winberg, M. L., Tamagnone, L., Bai, J., Comoglio, P. M., Montell, D., and Goodman, C. S. (2001). The transmembrane protein Off-track associates with Plexins and functions downstream of Semaphorin signaling during axon guidance. Neuron 32, 53-62. doi: 10.1016/s0896-6273(01)00446-9

Wu, J. H., Zhou, Y. F., Hong, C. D., Chen, A. Q., Luo, Y., Mao, L., et al. (2019). Semaphorin-3A protects against neointimal hyperplasia after vascular injury. EBioMedicine 39, 95-108. doi: 10.1016/j.ebiom.2018.12.023

Xin, H., Katakowski, M., Wang, F., Qian, J. Y., Liu, X. S., Ali, M. M., et al. (2017). MicroRNA cluster miR-17-92 cluster in exosomes enhance neuroplasticity and functional recovery after stroke in rats. Stroke 48, 747-753. doi: 10.1161/ STROKEAHA.116.015204

Xiong, X., Barreto, G. E., Xu, L., Ouyang, Y. B., Xie, X., and Giffard, R. G. (2011). Increased brain injury and worsened neurological outcome in interleukin-4 knockout mice after transient focal cerebral ischemia. Stroke 42, 2026-2032. doi: 10.1161/STROKEAHA.110.593772

Xu, J., Li, X., Yuan, Q., Wang, C., Xu, L., Wei, X., et al. (2021). The semaphorin 4Aneuropilin 1 axis alleviates kidney ischemia reperfusion injury by promoting the stability and function of regulatory T cells. Kidney Int. 100, 1268-1281. doi: 10.1016/j.kint.2021.08.023

Xu, S., Lu, J., Shao, A., Zhang, J. H., and Zhang, J. (2020). Glial cells: role of the immune response in ischemic stroke. Front. Immunol. 11:294. doi: 10.3389/ fimmu.2020.00294

Xu, Z., Wang, W., Ren, Y., Zhang, W., Fang, P., Huang, L., et al. (2018). Regeneration of cortical tissue from brain injury by implantation of defined molecular gradient of semaphorin 3A. Biomaterials 157, 125-135. doi: 10.1016/ j.biomaterials.2017.12.010

Xue, D., Desjardins, M., Kaufman, G. N., Beland, M., Al-Tamemi, S., Ahmed, E., et al. (2016). Semaphorin 4C: a novel component of B-Cell polarization in Th2Driven immune responses. Front. Immunol. 7:558. doi: 10.3389/fimmu.2016. 00558

Yang, L., Wang, L., Wang, J., and Liu, P. (2021). Long non-coding RNA Gm11974 aggravates oxygen-glucose deprivation-induced injury via miR-1225p/SEMA3A axis in ischaemic stroke. Metab. Brain Dis. 36, 2059-2069. doi: 10.1007/s11011-021-00792-7

Yang, S., Jin, H., Zhu, Y., Wan, Y., Opoku, E. N., Zhu, L., et al. (2017). Diverse functions and mechanisms of pericytes in ischemic stroke. Curr. Neuropharmacol. 15, 892-905. doi: 10.2174/1570159X15666170112170226

Yang, Y., Li, C., Wang, R., Wang, H., Ma, Q., He, Y., et al. (2019). Roles of Sema3A and VEGF165 in cortical neurons and vascular endothelial cells during oxygen glucose deprivation stimulation. Cell Mol. Biol. 65, 63-68.

You, T., Zhu, Z., Zheng, X., Zeng, N., Hu, S., Liu, Y., et al. (2019). Serum semaphorin 7A is associated with the risk of acute atherothrombotic stroke. J. Cell. Mol. Med. 23, 2901-2906. doi: 10.1111/jcmm.14186

Yu, R., Kim, N. S., Li, Y., Jeong, J. Y., Park, S. J., Zhou, B., et al. (2021). Vascular Sema3E-Plexin-D1 signaling reactivation promotes poststroke recovery through VEGF downregulation in mice. Transl. Stroke Res. 13, 142-159. doi: 10.1007/s12975-021-00914-4

Yukawa, K., Tanaka, T., Kishino, M., Yoshida, K., Takeuchi, N., Ito, T., et al. (2010). Deletion of Sema4D gene reduces intimal neovascularization and plaque growth in apolipoprotein E-deficient mice. Int. J. Mol. Med. 26, 39-44. doi: 10.3892/ijmm_00000432

Zhang, H. L., Wang, J., and Tang, L. (2014). Sema4D knockdown in oligodendrocytes promotes functional recovery after spinal cord injury. Cell Biochem. Biophys. 68, 489-496. doi: 10.1007/s12013-013-9727-0

Zhao, L., Zhang, M., Yan, F., and Cong, Y. (2021). Knockdown of RMST impedes neuronal apoptosis and oxidative stress in OGD/R-Induced ischemic stroke via depending on the miR-377/SEMA3A signal network. Neurochem. Res. 46, 584-594. doi: 10.1007/s11064-020-03194-w 
Zhou, H., Yang, Y. H., and Basile, J. R. (2014). The Semaphorin 4D-Plexin$\mathrm{B} 1-\mathrm{RhoA}$ signaling axis recruits pericytes and regulates vascular permeability through endothelial production of PDGF-B and ANGPTL4. Angiogenesis 17, 261-274. doi: 10.1007/s10456-013-9395-0

Zhou, Y. F., Chen, A. Q., Wu, J. H., Mao, L., Xia, Y. P., Jin, H. J., et al. (2019). Sema3E/PlexinD1 signaling inhibits postischemic angiogenesis by regulating endothelial DLL4 and filopodia formation in a rat model of ischemic stroke. FASEB J. 33, 4947-4961. doi: 10.1096/fj.201801706RR

Zhou, Y. F., Li, Y. N., Jin, H. J., Wu, J. H., He, Q. W., Wang, X. X., et al. (2018b). Sema4D/PlexinB1 inhibition ameliorates blood-brain barrier damage and improves outcome after stroke in rats. FASEB J. 32, 2181-2196. doi: 10. 1096/fj.201700786RR

Zhou, Y. F., Li, P. C., Wu, J. H., Haslam, J. A., Mao, L., Xia, Y. P., et al. (2018a). Sema3E/PlexinD1 inhibition is a therapeutic strategy for improving cerebral perfusion and restoring functional loss after stroke in aged rats. Neurobiol. Aging 70, 102-116. doi: 10.1016/j.neurobiolaging.2018.06.003

Zhu, L., Bergmeier, W., Wu, J., Jiang, H., Stalker, T. J., Cieslak, M., et al. (2007). Regulated surface expression and shedding support a dual role for semaphorin 4D in platelet responses to vascular injury. Proc. Natl. Acad. Sci. U.S.A. 104, 1621-1626. doi: 10.1073/pnas.0606344104

Zhu, L., Stalker, T. J., Fong, K. P., Jiang, H., Tran, A., Crichton, I., et al. (2009). Disruption of SEMA4D ameliorates platelet hypersensitivity in dyslipidemia and confers protection against the development of atherosclerosis.
Arterioscler. Thromb. Vasc. Biol. 29, 1039-1045. doi: 10.1161/ATVBAHA.109.1 85405

Zhu, Y. M., Lin, L., Wei, C., Guo, Y., Qin, Y., Li, Z. S., et al. (2021). The key regulator of necroptosis, RIP1 kinase, contributes to the formation of astrogliosis and glial scar in ischemic stroke. Transl. Stroke Res. 12, 991-1017. doi: 10.1007/s12975021-00888-3

Conflict of Interest: The authors declare that the research was conducted in the absence of any commercial or financial relationships that could be construed as a potential conflict of interest.

Publisher's Note: All claims expressed in this article are solely those of the authors and do not necessarily represent those of their affiliated organizations, or those of the publisher, the editors and the reviewers. Any product that may be evaluated in this article, or claim that may be made by its manufacturer, is not guaranteed or endorsed by the publisher.

Copyright (c) $2022 \mathrm{Du}, \mathrm{Xu}$ and Zhu. This is an open-access article distributed under the terms of the Creative Commons Attribution License (CC BY). The use, distribution or reproduction in other forums is permitted, provided the original author(s) and the copyright owner(s) are credited and that the original publication in this journal is cited, in accordance with accepted academic practice. No use, distribution or reproduction is permitted which does not comply with these terms. 